\title{
Interactions between vitamin $D$ status, calcium intake and parathyroid hormone concentrations in healthy pregnant women
}

\author{
A. Hemmingway ${ }^{1,2}$, K.M. O’Callaghan ${ }^{1,2}$, Á. Hennessy ${ }^{1,2}$ and M.E. Kiely ${ }^{1,2}$ \\ ${ }^{1}$ Cork Centre for Vitamin D and Nutrition Research and ${ }^{2}$ The Irish Centre for Fetal and Neonatal Translational \\ Research (INFANT), University College Cork, Ireland
}

Emerging evidence highlights the potential of the vitamin D and calcium metabolic system to impact pregnancy outcomes and adverse effects of vitamin D-parathyroid hormone $(\mathrm{PTH})$ interactions on perinatal health have been reported ${ }^{(1,2)}$. PTH concentrations reflect homeostasis in the calcium metabolic system, and can be impacted by calcium intake as well as circulating 25 -hydroxyvitamin $\mathrm{D}$ [ 25 $(\mathrm{OH}) \mathrm{D}]$ concentrations, reflecting vitamin D status. Little explored in pregnancy, we aimed to examine the relative importance of vitamin D status and calcium intake on PTH concentrations among healthy pregnant women.

This was a cross-sectional analysis of 142 white-skinned participants of mean (SD) 14 (2) weeks' gestation at baseline of a dose-response randomised controlled trial of vitamin D [NCT02506439] ${ }^{(3)}$. Serum 25(OH)D was measured by a CDC-accredited LC-MS/MS method and calcium intakes were estimated using a validated quantitative food frequency questionnaire ${ }^{(4)}$. Serum albumin-corrected calcium and intact PTH were measured by colorimetric assay (Randox Laboratories Ltd.) and ELISA (MD Biosciences Inc.), respectively. Serum $25(\mathrm{OH}) \mathrm{D}$ was stratified at $50 \mathrm{nmol} / \mathrm{L}$ and calcium intakes by $<800,800-1000$ and $\geq 1000 \mathrm{mg} / \mathrm{day}$ according to the Institute of Medicine ${ }^{(5)}$. After log transformation of PTH, we used Pearson's correlations and two-way ANOVA to explore effects of calcium intakes and $25(\mathrm{OH}) \mathrm{D}$ on PTH.

Geometric mean $(95 \%$ CI) PTH concentration was $9.24(8 \cdot 37,10 \cdot 19)$ pg/mL. Mean (SD) 25(OH)D and calcium intake were 54.9 $(22.6) \mathrm{nmol} / \mathrm{L}$ and $1182.5(485.8) \mathrm{mg} /$ day, respectively. $44 \%$ of participants had a $25(\mathrm{OH}) \mathrm{D}<50 \mathrm{nmol} / \mathrm{L}$ and calcium intake was $<800$ and $\geq 1000 \mathrm{mg} /$ day in $22 \%$ and $63 \%$, respectively. PTH was inversely correlated with vitamin D status $(\mathrm{r}=-0 \cdot 311, P<0 \cdot 01)$, but not calcium intake $(\mathrm{r}=-0.087)$ or serum calcium $(\mathrm{r}=0.057)$. There was no evidence of an interaction between calcium intake and $25(\mathrm{OH})$ D on PTH concentration $(P=0.941)$. There was a statistically significant main effect of serum $25(\mathrm{OH}) \mathrm{D}(P=0.025)$ but not calcium intake $(P=0 \cdot 822)$ on PTH.

To conclude, in this group of healthy pregnant women with largely sufficient calcium intake, vitamin D status, but not calcium intake was important for maintaining calcium homeostasis.

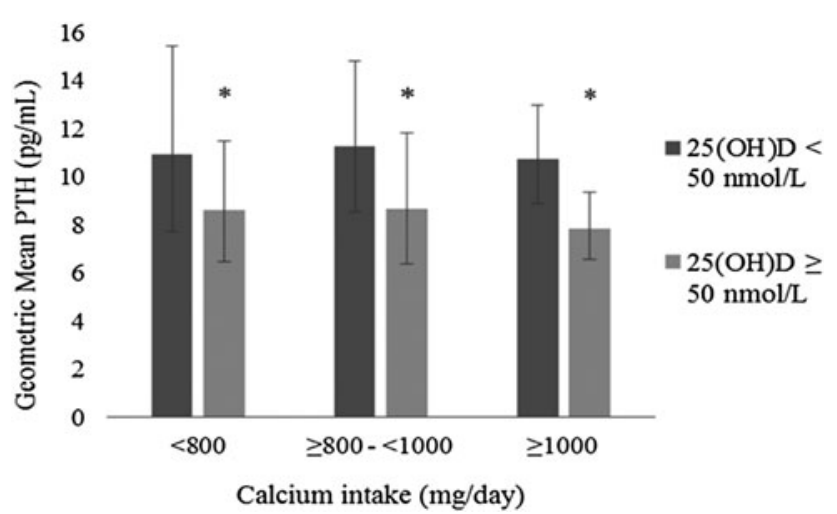

Fig. 1. PTH concentrations in 142 pregnant women stratified by vitamin D status and calcium intake. PTH values are geometric mean $(95 \% \mathrm{CI}) . *$ denotes $\mathrm{P}<0.05$

1. Kiely M, Hemmingway A \& O'Callaghan KM. (2017) Ther Adv Musculoskelet Dis 9(6), 145-54.

2. Scholl TO, Chen X \& Stein TP. (2013) Am J Clin Nutr 98(3), 787-93.

3. O'Callaghan KM, Hennessy Á, Hull GLJ et al. (2018) Am J Clin Nutr. DOI: nqy064 In Press

4. Kiely M, Collins A, Lucey AJ, et al. (2016) J Hum Nutr Diet 29(4), 495-504.

5. Institute of Medicine (2011). Washington (DC): National Academies Press. 